\title{
A REMARK ON CERTAIN P-VALENT FUNCTIONS
}

\author{
M. K. AOUF and H. E. DARWISH \\ Department of Mathematics, Faculty of Science \\ University of Mansoura, Mansoura Egypt
}

(Received May 3, 1994)

ABSTRACT. The object of the present paper is to prove an interesting result for certain analytic and p-valent functions in the unit disc $U=\{z:|z|<1\}$.

KEY WORDS AND PHRASES. Analytic, p-valent, Ruscheweyh derivative. 1991 AMS SUBJECT CLASSIFICATION CODES. 30C45.

\section{INTRODUCTION.}

Let $A(p)$ denote the class of functions of the form

$$
f(z)=z^{p}+\sum_{k=p+1}^{\infty} a_{k} z^{k} \quad(p \in N=\{1,2, \ldots\})
$$

which are analytic and $p$-valent in the unit disc $U=\{z:|z|<1\}$. For functions $f_{j}(z)(j=1,2)$ defined by

$$
f_{j}(z)=z^{p}+\sum_{k=p+1}^{\infty} a_{k, j} z^{k},
$$

we define the convolution product $f_{1} * f_{2}(z)$ of functions $f_{1}(z)$ and $f_{2}(z)$ by,

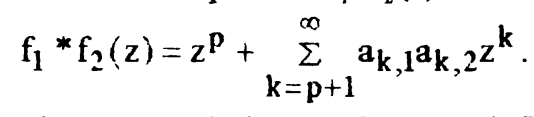

Using the above convolution product, we define

$$
D^{n+p-1} f(z)=\left(\frac{z^{p}}{(1-z)^{n+p}}\right) * f(z) \quad(f(z) \in A(p)),
$$

where $n$ is any integer greater than $-p$. We note that

$$
D^{n+p-1} f(z)=\frac{z^{p}\left(z^{n-1} f(z)\right)^{(n+p-1)}}{(n+p-1) !}
$$

The symbol $D^{n+p-1}$ when $p=1$ was introduced by Ruscheweyh [8], and the symbol $D^{n+p-1}$ was introduced by Goel and Sohi [5]. This symbol was named the Ruscheweyh derivative of $(n+p-1)$ - th order by Chen and Owa [4].

It follows from (1.5) that

$$
z\left(D^{n+p-1} f(z)\right)^{\prime}=(n+p) D^{n+p} f(z)-n D^{n+p-1} f(z) \quad(c f .[4] \text { and [5]). }
$$

Recently, Chen and Lan ([1] , [2]), Chen, Lee and Owa [3], Chen and Owa [4] and Srivastava. Owa and Pashkouleva [9] have been proved some interesting results of analytic functions involving Ruscheweyh derivatives. In the present paper, we prove an interesting result for functions $f(z) \in A(p)$ satisfying 


$$
\operatorname{Re}\left\{\frac{D^{n+p+1} f(z)}{z^{p}}\right\}>\alpha, \quad 0 \leq \alpha<1 \text { and } n \in N_{0}=N \subset\{0\}
$$

\section{MAIN RESULT.}

In order to prove our main result, we recall here the following lemma:

\section{LEMMA (Miller [6]; Miller and Mocanu [7]) .}

Let $\varphi(u, v)$ be a complex - valued function,

$$
\varphi: D \rightarrow C, D=C, C \quad \text { (C is the complex plane), }
$$

and let $u=u_{1}+i u_{2}, v=v_{1}+i v_{2}$. Suppose that the function $\varphi(u, v)$ satisfies the following conditions:

(i) $\varphi(u, v)$ is continuous in $D$;

(ii) $(1,0) \in \mathrm{D}$ and $\operatorname{Re}\{\varphi(1,0)\}>0$;

(iii) $\operatorname{Re}\left\{\phi\left(\mathrm{iu}_{2}, \mathrm{v}_{1}\right)\right\} \leq 0$ for all $\left(\mathrm{iu}_{2}, \mathrm{v}_{1}\right) \in \mathrm{D}$ and such that $\mathrm{v}_{1} \leq-\frac{\left(1+\mathrm{u}_{2}^{2}\right)}{2}$.

Let $q(z)=1+q_{1} z+q_{2} z^{2}+\cdots$ be regular in the unit disc $\left(I\right.$ such that $\left(q(z), z q^{\prime}(z)\right)$ $\in D$ for all $z \in U$. If

then

$$
\operatorname{Re}\left\{\varphi\left(q(z), z^{\prime}(z)\right)\right\}>0 \quad(z \in U),
$$

$$
\operatorname{Re}\{q(z)\}>0 \quad(z \in U) .
$$

Applying the above Lemma, we derive the following:

THEOREM. Let the function $f(z)$ be in the class $A(p)$ satisfy

$$
\operatorname{Re}\left\{\frac{D^{n+p+1} f(z)}{z^{p}}\right\}>\alpha, \quad(z \in U)
$$

for $0 \leq \alpha<1$ and $n \in N_{0}$. Then

$$
\operatorname{Re}\left\{\sqrt{\frac{D^{n+p} f(z)}{z^{p}}}\right\}>\beta, \quad(z \in U)
$$

where

$$
\beta=\frac{1+\sqrt{1+4 \alpha(n+p+1)(n+p+2)}}{2(n+p+2)}
$$

PROOF. For $f(z)$ in $A(p)$, we define the function $q(z)$ by

$$
\sqrt{\frac{D^{n+p} f(z)}{z^{p}}}=\beta+(1-\beta) q(z),
$$

where $\beta$ is given by (2.3). Then $q(z)$ is regular in $U$ and $q(z)=1+q_{1} z+q_{2} z^{2}+\ldots \ldots$. Taking the derivatives of both sides in (2.4), we have

$$
\frac{z\left(D^{n+p} f(z)\right)^{\prime}-p\left(D^{n+p} f(z)\right)}{z^{p}}=2(1-\beta)[\beta+(1-\beta) q(z)] z q^{\prime}(z) \text {. }
$$


Since the identity ( 5 ) imples

$$
z\left(D^{n+p} f(z)\right)^{\prime}=\left(n+p+1 i D^{n+p+1} f(z)-(n+1) D^{n+p} f(z)\right.
$$

(25) becomes

$$
\frac{D^{n+p+1} f(z)}{z^{p}}=[\beta+(1-\beta) q(z)]^{2}+\frac{2(1-\beta)[\beta+(1-\beta) q(z)] z q^{\prime}(L)}{(n+p+1)}
$$

or

$$
\operatorname{Re}\left\{\frac{D^{n+p+1} f(z)}{z^{p}}-\alpha\right\}=\operatorname{Re}\left\{[\beta+(1-\beta) q(z)]^{2}+\frac{2(1-\beta)(\beta+(1-\beta) q(z)] z q^{\prime}(z)}{(n+p+1)}-\alpha\right\}<0 .
$$

Takung $q(z)=u=u_{1}+u_{2}$ and $z q^{\prime}(z)=v=v_{1}+v_{2}$, we define the function $\varphi(u, v)$ by

$$
\varphi(u, v)=[\beta+(1-\beta) u]^{2}+\frac{2(1-\beta)[\beta+(1-\beta) u] v}{(n+p+1)}-\alpha .
$$

Then it follows from (2.9) that

(i) $\varphi(u, v)$ is continuous in $D=C \times C$,

(ii) $(1,0) \in \mathrm{D}$ and $\operatorname{Re}\{\varphi(1,0)\}=1-\alpha>0$,

(iii) for all $\left(\mathrm{iu}_{2}, \mathrm{v}_{1}\right) \equiv \mathrm{D}$ such that $\mathrm{v}_{1}:-\frac{\left(1+\mathrm{u}_{2}^{2}\right)}{2}$,

$\operatorname{Re}\left\{\varphi\left(1 \mathrm{u}_{2}, \mathrm{v}_{1}\right)\right\}=\beta^{2}-(1-\beta)^{2} \mathrm{u}_{2}^{2}+\frac{2 \beta(1-\beta) \mathrm{v}_{1}}{(\mathrm{n}+\mathrm{p}+1)}-\alpha$

$$
\begin{aligned}
& \leq \beta^{2}-(1-\beta)^{2} u_{2}^{2}-\frac{\beta(1-\beta)\left(1+u_{2}^{2}\right)}{(n+p+1)}-\alpha \\
& <0
\end{aligned}
$$

for $0 \leq \alpha<1, n \in N_{0} \quad, n>-p$ and $\beta$ is given by (2.3). Therefore, the function $\varphi(u, v)$ satisfies the conditions in the lemma. Thus we have $\operatorname{Re}\{q(z)\}>0(z \in L)$, that is ,

$$
\operatorname{Re}\left\{\sqrt{\frac{D^{n+p} f(z)}{z^{p}}}\right\}>\beta=\frac{1+\sqrt{1+4 \alpha(n+p+1)(n+p+2)}}{2(n+p+2)}
$$

which completes the proof of the Theorem.

Letting $\alpha=0$, the theorem gives:

COROLLARY 1. Let the function $f(z)$ be in the class $A(p)$ satisfy

$$
\operatorname{Re}\left\{\frac{D^{n+p+1} f(z)}{z^{p}}\right\}>0 \quad(z \in U)
$$

for $n \in N_{0}$ and $n>-p$. Then

$$
\operatorname{Re}\left\{\sqrt{\frac{D^{n+p} f(z)}{z^{p}}}\right\}>\frac{1}{(n+p+2)} \quad(z \in U) .
$$

Taking $n=1-p$ in the above theorem, we have 
COROLLARY 2. Let the function $f(z)$ be in the class $A(p)$ satisty

$$
\operatorname{Re}\left\{\frac{D^{2} f(z)}{z^{p}}\right\}, \alpha \quad(z \equiv U)
$$

for $0 \leq \alpha<1$ and $p \equiv N$. Then

$$
\operatorname{Re}\left\{\sqrt{\frac{z f^{\prime}(z)+(1-p) f(z)}{z^{1}}}\right\}>-\frac{1+\sqrt{1+24 \alpha}}{6}
$$

REMARK 1. Putting $\mathrm{p}=1$ in the above results, we get the results obtained by Chen, Lee and Owa [3].

REMARK 2. Using the same technique as in the theorem (or putting $\frac{\mathrm{zf}^{\prime}(z)}{\mathrm{p}}$ instead of $f(z)$ in the theorem), we have the following result :

COROLLARY 3. Let the function $f(z)$ be in the class $A(p)$ satisfy

$$
\operatorname{Re}\left\{\frac{\left(\mathrm{D}^{\mathrm{n}+\mathrm{p}+1} \mathrm{f}(\mathrm{z})\right)^{\prime}}{p z^{\mathrm{p}-1}}\right\}>\alpha \quad(\mathrm{z} \in \mathrm{U})
$$

for $0 \leq \alpha<1$ and $n \in N_{0}$. Then

$$
\operatorname{Re}\left\{\sqrt{\frac{\left(D^{n+p} f(z)\right)^{\prime}}{p z^{p-1}}}\right\}>\beta
$$

where $\beta$ is given by (2.3)

\section{REFERENCES}

1. CHEN, M. -P. and LAN, I. -R. On certain inequalities for some regular functions defined on the unit disc, Bull. Austral. Math. Soc. 35 (1987), 387 - 396.

2. CHEN, M.-P. and LAN , I.-R. On $\alpha$-convex functions of order $\beta$ of Ruscheweyh type, Internat. J. Math. Math. Sci. 12 (1989), $107-112$.

3. CHEN, M.-P., LEE, S.-K. and OWA, S. A remark on certain regular functions, Simon Stevin 65 (1991), no. 1-2, 23- 30.

4. CHEN, M.-P. and OWA, S. A property of certain analytic functions involving Ruscheweyh derivatives, Proc. Japan Acad. 65 Ser.A (1989), no.10,333335 .

5. GOEL, R. M. and SOHI, N. S. A new criterion for $\mathrm{p}$-valent functions , Proc. Amer. Math. Soc. 78 (1980), 353- 357.

6. MILLER, S. S. Differential inequalities and Caratheodory function, Bull. Amer. Math. Soc. 8 (1975), 79-81.

7. MILLER, S. S. and MOCANU, P T. Second order differential inequalities in the complex plane, J. Math. Anal. Appl. 65 (1978), 289 - 305.

8. RUSCHEWEYH, St. New criteria for univalent functions , Proc. Amer. Math. SOC. 49 (1975) . $109-115$.

9. SRIVASTAVA H. M., OWA, S. and PASHKOUlEVA, D. Z. Some inequalities associated with a class of regular functions, Utilitas Math. 34 (1988), 163-168. 


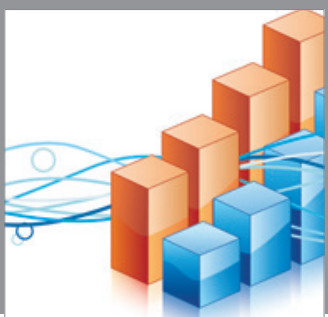

Advances in

Operations Research

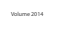

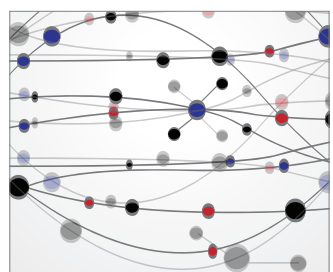

\section{The Scientific} World Journal
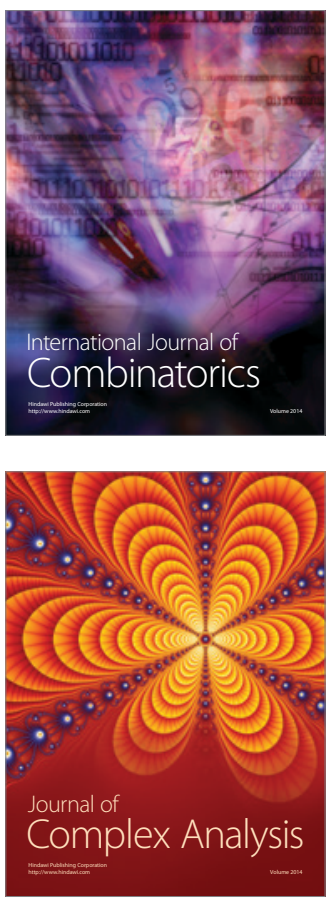

International Journal of

Mathematics and

Mathematical

Sciences
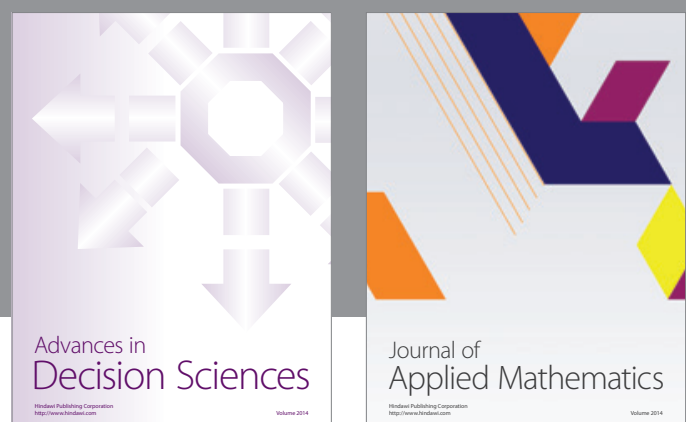

Journal of

Applied Mathematics
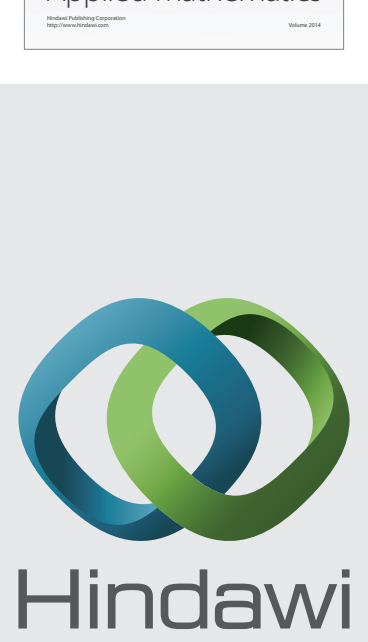

Submit your manuscripts at http://www.hindawi.com
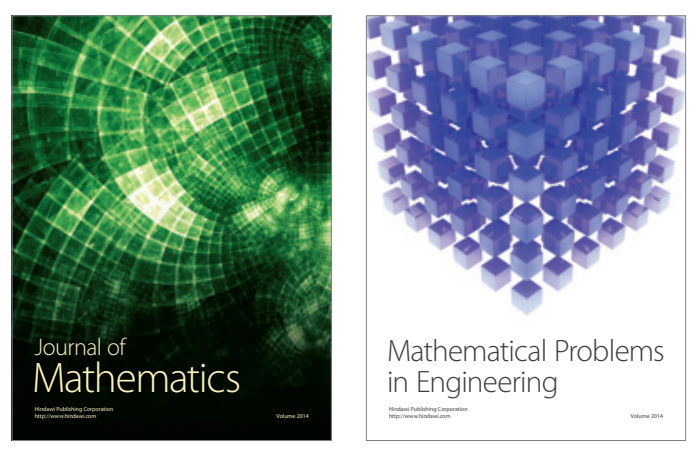

Mathematical Problems in Engineering
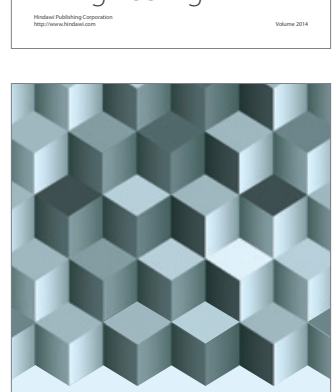

Journal of

Function Spaces
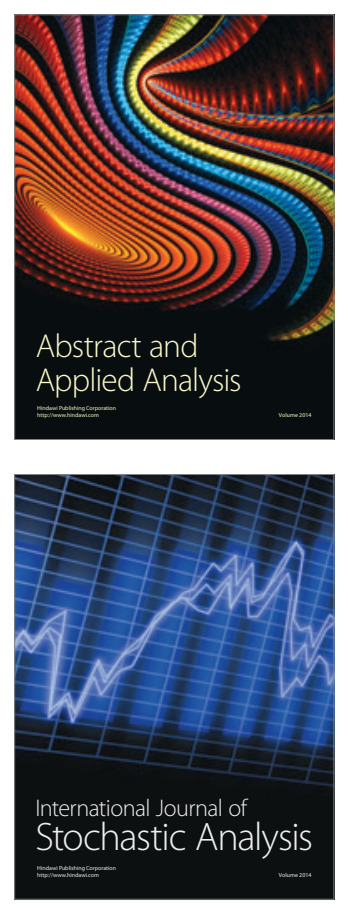

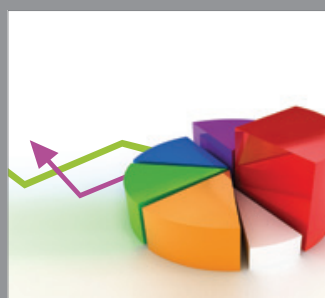

ournal of

Probability and Statistics

Promensencen
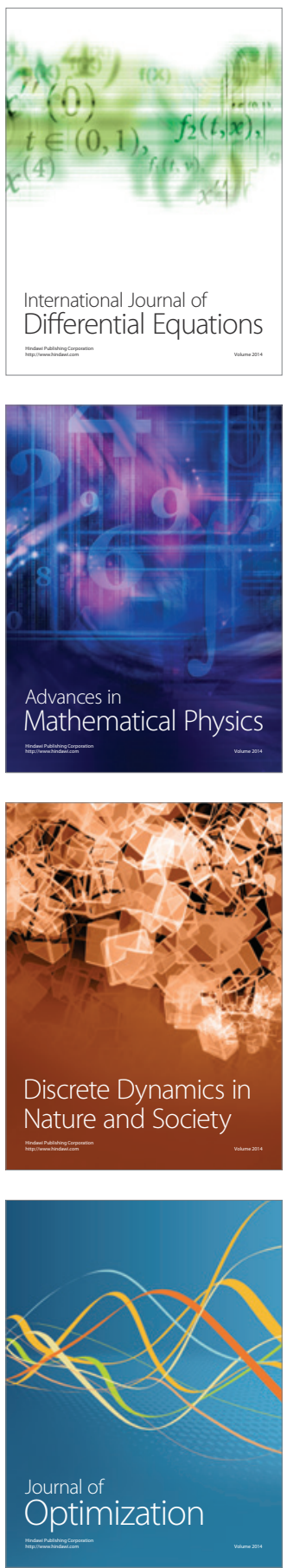